
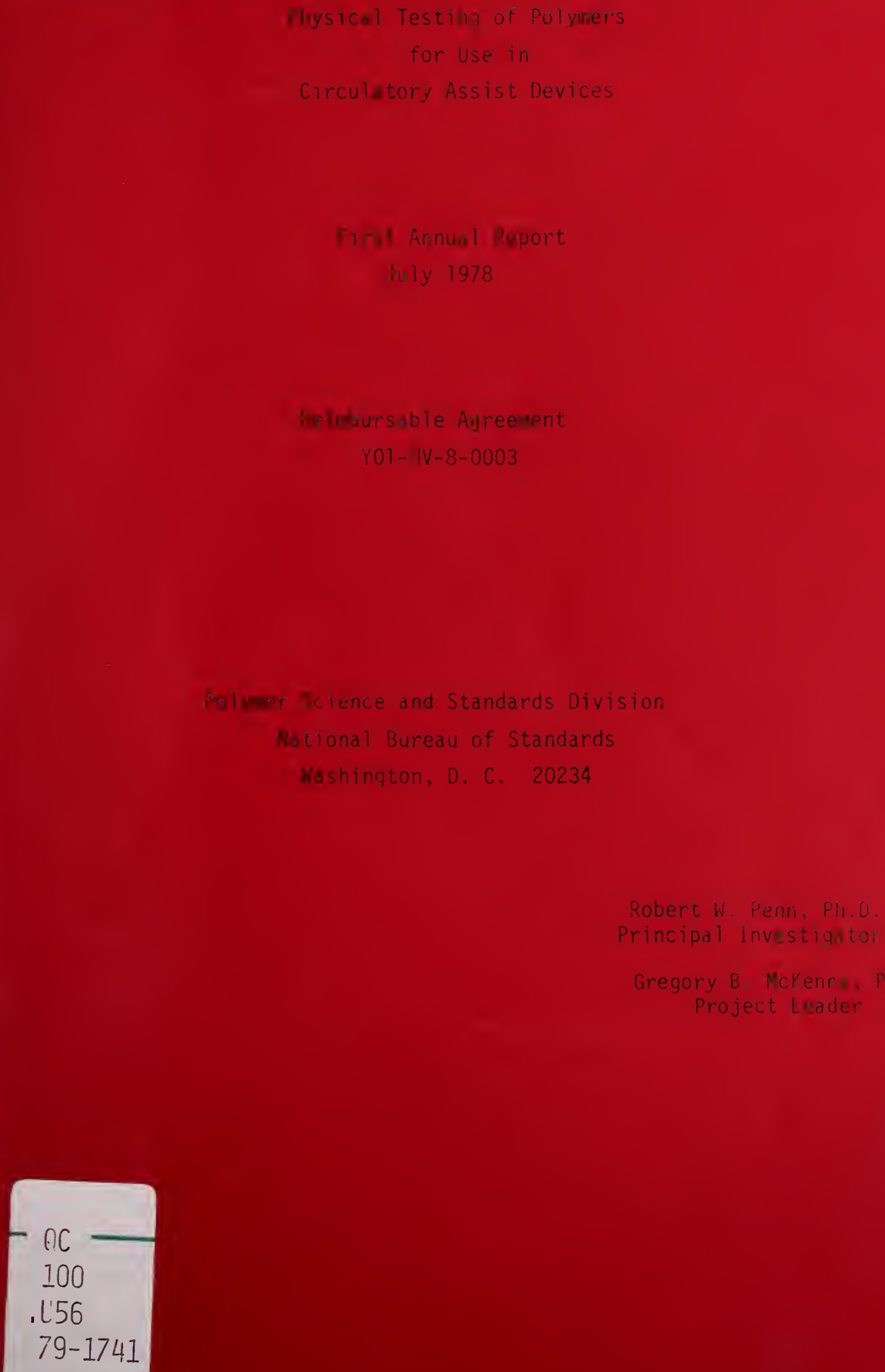



\section{Physical Testing of Polymers \\ for Use in \\ Circuiatory Assist Devices}

First Annual Report

July 1978

To: Devices and Technology Branch

Division of Heart and Vascular Diseases

National Heart, Lung, and Blood Institute

National Institutes of Health

Reimbursable Agreement

Y01-HV-8-0003

Polymer Science and Standards Division

National Bureau of Standards

Washington, D. C. 20234

Robert W. Penn, Ph.D.

Principal Investigator

Gregory B. McKenna, Ph.D.

Project Leader 
Abstract

The concept of linear additive damage has been used to relate sinusoidal fatigue data with creep failure time data on two polymers. Deviations of fatigue data from predictions made from creep failure time data were found to be in opposite directions for a glassy and a semicrystalline polymer. Further work will extend this study to elastomers and candidate biocompatible materials.

The limited quantities of candidate materials have permitted preliminary measurements of constant strain rate and creep tests. Specimens of a urethane-silicone copolymer were obtained from rejected intra-aortic balloons. These specimens were characterized by Fourier transform infrared attenuated total reflection spectroscopy, as well as by optical microscopy. Significant differences between the two durfaces of the intra-aortic balloon were observed. The use of difference spectroscopy has permitted a more detailed characterization of the surfaces.

Optical microscopy has revealed circular features near the surface of the ba 1100 wall (which we are tempted to characterize as regions of segregated poly(dimethyl siloxane) (PDMS)) on a much grosser scale than has been previously reported.

We have prepared carefully controlled samples of an NBS standard butyl rubber and distributed test specimens to other investigators involved in physical testing of polymers for use in circulatory assist devices. This material has mechanical properties similar to candidate biocompatible materials and may be useful as an interlaboratory standard and for test method development.

Preliminary design and construction of a biaxial fatigue test cell has been completed. Fatigue experiments on butyl rubber using this device have indicated that only minor modifications will be necessary before initiation of fatigue testing on candidate biomaterials. A multiposition test station for these cells is being assembled. 


\section{Preface}

This report presents results obtained in the past year in a research program on Physical Testing of Polymers for use in Circulatory Assist Devices carried out at the National Bureau of Standards with the support of the National Heart, Lung and Blood Institute of the National Institutes of Health. The report covers work performed in the period October 1, 1977 to June 30, 1978. The research was somewhat hampered by the lack of samples of candidate biocompatible materials, and the originally proposed research plan could not be followed closely. Steps have been taken to secure biocompatible materials from suppliers and the work plan for the second year effort is modified to include physical testing of these materials. Our objectives were refocused toward other aspects of the problem which were accessible. 


\section{List of Tables}

Page

1. Failure Times for Poly(methyl methacrylate) 4

2. NBS Reference Butyl Rubber Compound 9

3. Permanent Set of Elastomers after Straining 16

4. Comparison of IR Band Frequencies of PDMS and Those Obtained 25 in the Difference Spectrum. 

Table of Contents

Page

Title Page

Preface

i

Abstract

i i

Table of Contents

i i i

List of Tables

iv

List of Figures

v

1. Introduction

2. Theoretical Framework

3. Preliminary Mechanical Characterization of Elastomers

4. Characterization of the Urethane-Silicone Film by Infrared Spectroscopy

5. Optical Microscopy Study of the Urethane-SiTicone Film

6. Biaxial Fatigue Cell Development 
1. Failure Kinetics for PMMA and PE

2. Stress Strain Behavior for Elastomers

3. Mooney Rivlin Plot for the Urethane-Silicone Copolymer

4. for Polyolefin

$5 . \quad 11$

for NBS Butyl Rubber

6. Creep of NBS Butyl Rubber in Air

7. 1

" $0.15 \mathrm{~N}$ Saline

8. Infrared Spectroscopy of Urethane-silicone Film

9. Photomicrograph of Urethane-Silicone Balloon Wall

10. $"$

$"$

II

"I

"

"1

11. Biaxial Test Cell

12. Calibration Curve for Biaxial Test Cell

13. Oscilligram of Pressure Pulses 


\section{Introduction}

This report presents preliminary results directed toward the objectives of developing test procedures and the evaluation of candidate materials for use in circulatory assist devices (CAD). The test procedures should permit the use of accelerated tests to predict material performance over long time intervals from relatively short time tests. Such extrapolation of test results must rely on a verified theoretical basis. We present one such basis in Section 2.

The research program was hampered by the very limited supply of candidate materials available. A number of reject intra-aortic balloons were made available by Dr. Nyilas of AVCO Everett Laboratories. This material was only eight mils thick as compared with 25 to $40 \mathrm{mil}$ material desired for the CAD program. One half square foot of Polyolefin was made available by Dr. McMillin of Monsanto Research Corporation. This material did not have the biocompatible porous surface treatment. No Biomer film was made available. To permit some progress in test method development, we have prepared an ASTM formulation of NBS standard butyl rubber with mechanical properties in the same range as the candidate biocompatible materials.

This compound has a known history of good property uniformity.

Section 3 presents the results of some preliminary mechanical characterization tests on samples of the two candidate blood compatible materials as well as on the butyl rubber compound.

Sections 4 and 5 present the results of a microscopic and spectroscopic examination of the intra-aortic balloon material and Section 6 presents preliminary results toward the development of a biaxial fatigue test apparatus. 


\section{Theoretical Framework for the Prediction of Durability}

In order to predict the useful life of a mechanical component from some set of laboratory tests we need a concept or theoretical structure by which failure can be predicted. For many materials, the lifetime of specimens is found to depend upon the stresses to which they are subjected. This fact, alone, suggests that some damage mechanism occurs in the material which eventually produces failure. The simplest test which might be used to study the damage mechanism is creep to failure under constant stress.

Coleman, [1], for example, has studied the failure of nylon fibers and analyzed his results in terms of absolute reaction rate theory. He has also presented a phenomenological analysis of the time dependence of mechanical breakdown using the statistics of extreme values, [2]. For materials which he calls Class A for which the rate of damage accumulation depends only on the

current stress (and not on the current value of the damage) he predicts that the coefficient of variation (the standard deviation divided by the mean) for the breaking times will be independent of stress. For such materials whose lifetime at constant stress is known, failure in other stress histories can be described by what we have come to call the Bailey criterion:

$$
\int_{0}^{t_{B}} \frac{d \tau}{\tau_{B}(\sigma(\tau))}=1
$$

This is probably the simplest expression of a general linear additive damage law. The function $\tau_{B}(\sigma)$ can be obtained from observations of the lifetimes of samples held at constant stress. For many materials this function is found to be exponential in stress:

$$
\tau_{B}=A \operatorname{EXP}(-B \sigma)
$$

and the logarithm of the breaking time varies linearly with the stress. 
The integral (eq. 1) can then be evaluated for any history of stress to predict the failure time. For example, for a sinusoidally varying stress

$$
\sigma=\frac{\sigma_{0}}{2}(1+\sin \omega t)
$$

(when failure occurs after a large number of cycles), the time to fail,

$$
\hat{\tau}_{B}=\frac{\tau_{B}}{e^{-B \sigma / 2} I_{0}\left(B \sigma_{0} / 2\right)}
$$

where $\tau_{B}$ is the time to break for a constant stress equal to the peak stress and $I_{0}$ is the zeroth order modified Bessel function. Thus, the failure time is predicted to be independent of the frequency of the loading. Further, the same statistics apply and the same coefficients of variation and skewness should be found as for the constant stress tests.

We have attempted to test these predictions experimentally using two materials which were readily available: poly(methyl methacrylate) (PMMA) and poly(ethylene) (PE). Dumbell samples were cut from a sheet approximately $1.5 \mathrm{~mm}$ thick with a gage length of $5 \mathrm{~cm}$ and a width of $1.25 \mathrm{~cm}$. The samples were tested at controlled engineering stress in a servo hydraulic test machine with both constant and sinusoidally varying stresses. The frequency of the oscillating stresses was held below 0.2 Hertz to reduce the effect of hysteretic heating. The tests were run at room temperature $\left(24^{\circ} \mathrm{C}\right)$ at $50 \% \mathrm{RH}$. Since it is known that PMMA is very sensitive to humidity, the samples were stored for at least two weeks at these conditions before testing.

The results of these tests for PMMA are presented in Table 1 and summarized in Figure 1a. For constant stress, the sample lifetimes are found to follow equation 2 quite accurately with $A=1.5 \times 10^{10} \mathrm{sec}$ and $B=0.26 \mathrm{MPa}^{-1}$. The coefficient of variation is found to be nearly constant over the range studied at approximately 0.3. For the oscillating loads at high stresses, the failure times are approximately those predicted by Equation 4 but at low stresses the failure times are significantly shorter than predicted. At low stresses the coefficients of variation are about 
Table 1

Failure of Poly(Methyl methacrylate)

\section{Constant Load}

Peak

Stress

(MPa)

55.2

58.6

62.1

65.5

69.0

72.4

75.8

82.7

55.2

62.1

69.0

75.8

82.7
10

19

17

14

6
18026

5125

1549

257.9

25.8

Number
of
Specimens

10

9

10

10

13

15

30

3

\begin{tabular}{l} 
Mean Time \\
to Fail \\
(seconds) \\
\hline
\end{tabular}

12785

.353

.233

.364

.172

.239

.311

.456

35.5

.77
Moment Coefficient of Skewness

0.44

0.14

$-0.43$

$-0.16$

0.20

$-0.47$

$-0.05$

Sinusoidal Load, $0.164 \mathrm{~Hz}$

.449

.579

.783

.840

.868
0.46

0.60

0.41

1.42

0.82 


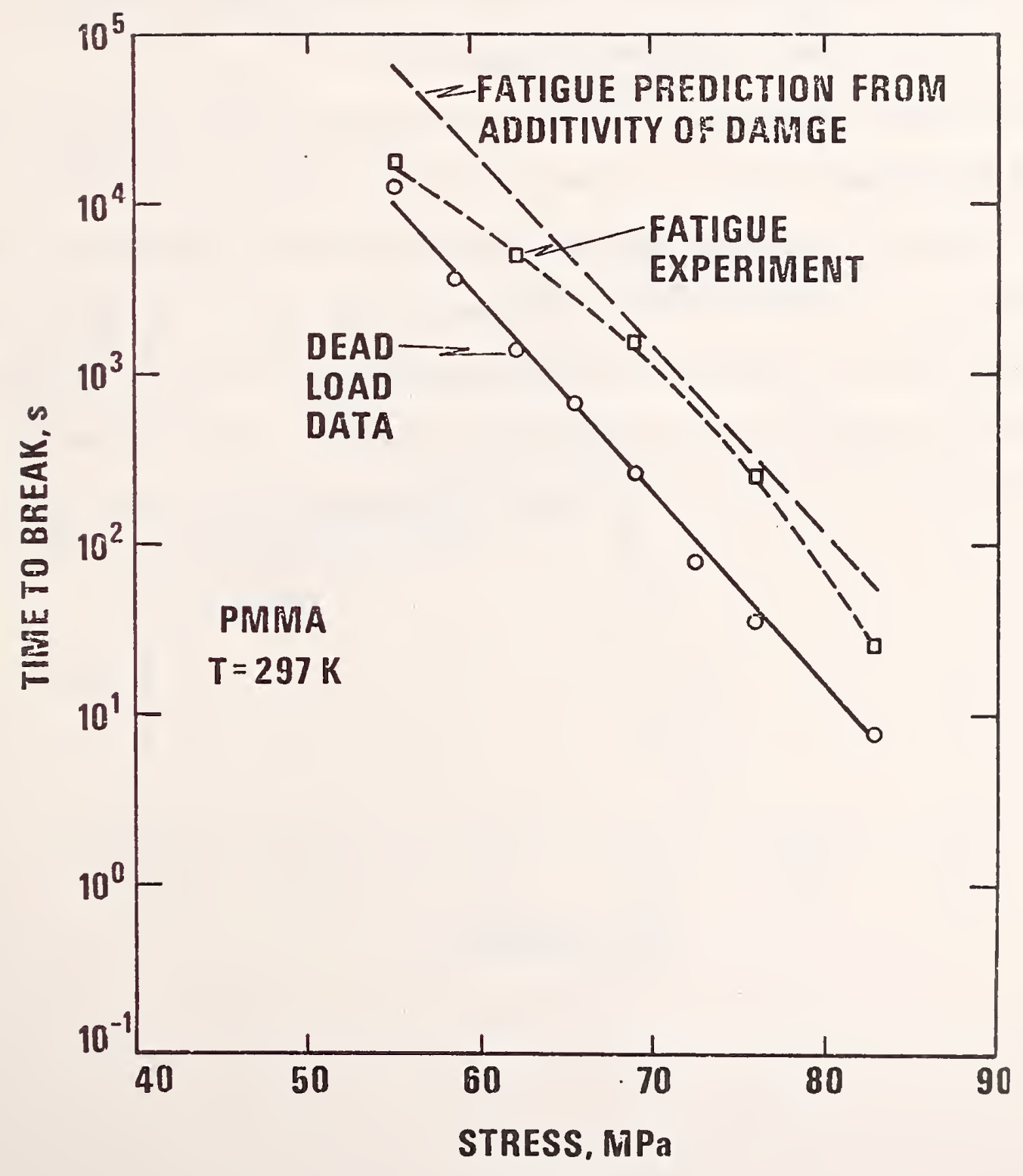

Fig. la. Failure kinetics for PMMA. Time to break vs. stress for dead load and fatigue experiments are compared with the time to break predicted for a fatigue experiment from the linear additivity of damage and the dead load data. 
the same as for the constant load measurements, but they increase regularly with load to nearly 1.0 at the highest loads studied.

Similar results are found for the coefficient of skewness, $m_{3} / m_{2}{ }^{3 / 2}$, where $m_{2}$ and $m_{3}$ are the second and third moments of the distribution respectively. For the constant load case, there seems to be no significant skewness while the sinusoidal load data appear to be positively skewed.

The few results obtained for a linear polyethylene sample are shown in Figure $1 \mathrm{~b}$. * Insufficient measurements have been taken for reliable statistical study, but the indication is that the deviation from the predicted behavior is opposite to that found for PMMA. The extrapolation of the creep failure data to fatigue of these materials would yield a dangerously optimistic prediction for the case of PMMA and a pessimistic prediction for the case of polyethylene. This work will be extended to include elastomers and the candidate CAD materials.

* Lifetinies for constant stress were obtained previously by Dr. J. M. Crissman of this laboratory. 


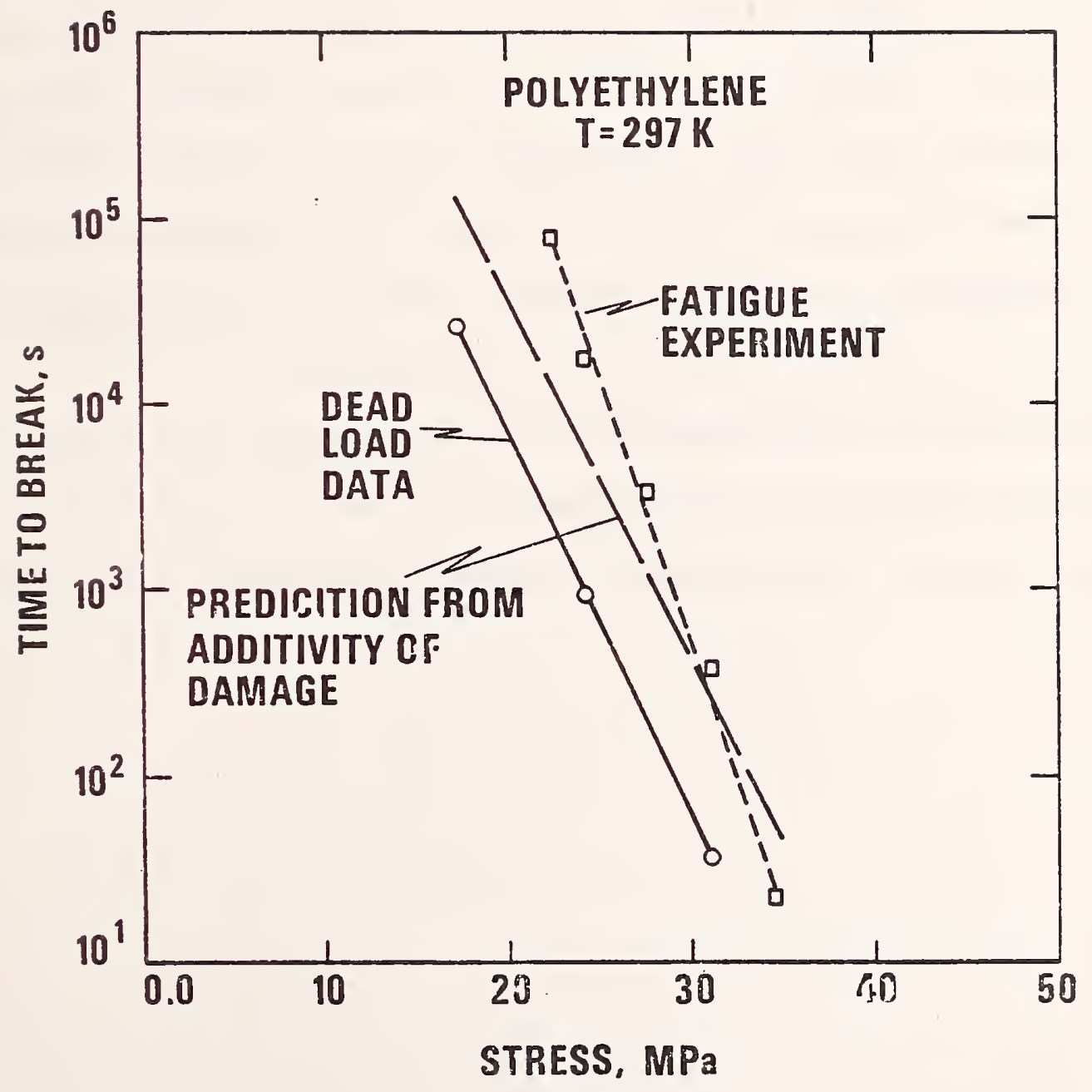

Fig. 1b. Failure kinetics for polyethylene. Time to break vs. stress for dead load and fatigue experiments are compared with the time to break predicted for a fatigue experiment from the linear additivity of damage and the dead load data. 
3. Preliminary Mechanical Characterization of Elastomers

A. Introduction

We were able to obtain small quantities of two candidate CAD materials, Avcothane 51* (urethane-silicone copolymer) and the Goodyear Polyolefin* elastomers. These permitted us to conduct preliminary mechanical characterization tests. In addition, we decided to produce our own "internal standard" elastomer using the NBS 388j Standard Reference Butyl* Resin compounded according to ASTM D-3188-73 Formula 1 A. This formulation was chosen as a material with properties in the range of those of the candidate CAD materials and because we have a known history of good property uniformity and reproducibility. Table 2 lists the formula used.

Two types of constant deformation rate tests were run on all three materials to provide an initial comparison of the mechanical properties. In addition, preliminary creep data have been obtained on the NBS Butyl Rubber in air and in $0.15 \mathrm{~N}$ Saline at $23 \pm 1^{\circ} \mathrm{C}$.

*Certain commercial materials and equipment are identified in this paper in order to specify adequately the experimental procedure. In no case does such identification imply recommendation or endorsement by the National Bureau of Standards, nor does it imply necessarily the best available for the purpose.

8 


\section{Table 2}

Compounding Formulation for NBS Butyl Rubber

\section{Ingredient}

NBS 388 j Butyl Rubber

NBS 370 e Zinc Oxide

NBS $371 \mathrm{~g}$ Sulfur

NBS $372 h$ Stearic Acid

NBS 378b 0il Furnace Black

NBS $374 \mathrm{C}$ Tetramethyl thiuram Disulfide
Quantity

Parts by Mass

100

3.00

1.75

1.00

50.00

1.00 
B. Constant Rate of Deformation Tests

Two different types of constant rate of deformation test were run on the three elastomers. First, all the materials were tested in a standard fashion by using dumbbell specimens with a $2.54 \mathrm{~cm}$ gage length and pulling them to failure on a Tinius 0lson* testing machine at a crosshead displacement rate of $51 \mathrm{~cm} / \mathrm{min}$. The Butyl and Polyolefin materials showed no grain effect due to the milling procedure. The urethane-silicone was tested by cutting dumbbells longitudinally from intra-aortic balloons provided by Dr. Nyilas of Avco. Figure 2 shows the engineering stress-elongation behavior for each of the materials. Figure 2 illustrates some differences in the behavior of the three materials. The urethane-silicone is quite stiff at low elongations and has a high ultimate strength $(44.3 \mathrm{MPa})$ and elongation to failure $(550 \%)$. The Polyolefin rubber, on the other hand, has a low initial stiffness which increases above that of the urethane-silicone at intermediate elongations. However, this material is characterized by a low elongation to failure (340\%) and an ultimate strength which is considerably lower that that of the urethane-silicone at $17.5 \mathrm{MPa}$. The NBS Butyl can be seen to have the lowest initial modulus. It shows an intermediate ultimate strength (21.5 MPa) and the highest elongation to failure $(600 \%)$.

Our comment on these results is that they point up some differences in the way in which the materials react under a forced deformation. Their behavior under oscillating loads can also be expected to be somewhat different.

In order to get some additional information about the nature of the materials, we performed another type of constant rate of deformation test. Dumbbell specimens of each material were deformed at $0.1 \mathrm{~cm} / \mathrm{min}$ to a deformation of $200-250 \%$. The specimens were then unloaded at the same rate. Rather than plot a conventional hysteresis loop, we chose to present the data on a so-called Mooney-Rivlin [3] plot of reduced stress, $\sigma_{r}$, versus $1 / \lambda$ where:

*Certain commercial materials and equipment are identified in this paper in order to specify adequately the experimental procedure. In no case does such identification imply recommendation or endorsement by the National Bureau of Standards, nor does it imply necessarily the best available for the purpose. 


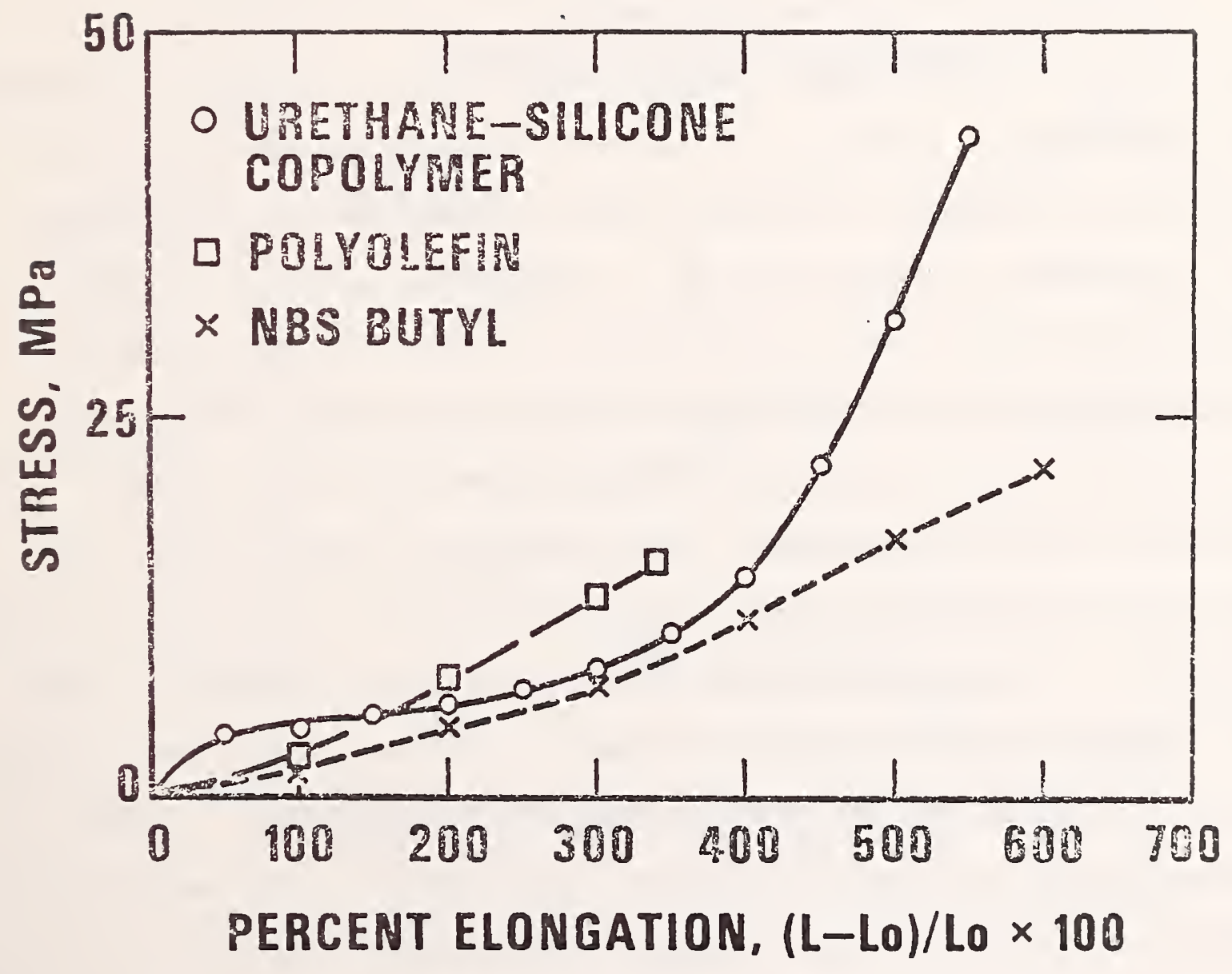

Fig. 2. Stress strain behavior of the urethane-silicone, Polyolefin and NBS Butyl Rubbers. The tests were run in air at $23^{\circ} \mathrm{C}$ at a deformation rate of $51 \mathrm{~cm}$ per ini nute. 
$\sigma_{R}=P / 2 A\left(\lambda-1 / \lambda^{2}\right)=\frac{\partial W}{\partial I_{1}}+1 / \lambda \frac{\partial W}{\partial I_{2}}$

$\lambda=\frac{L}{L_{0}}$

$L=$ instantaneous length of specimen

$L_{0}=$ initial length of specimen

$W=$ strain energy function

$I_{j}=i^{\text {th }}$ invariant in the principds stretches

$P$ is the load and $A$ is the original cross sectional area. If the material is elastic and can be represented as a Mooney-Rivlin material, then the data would plot as a straight line on this type of plot and the slope would give $\frac{\partial W}{\partial \mathrm{I}_{2}}$ and the intercept with the $1 / \lambda$ axis equal to 0 would give $\frac{\partial W}{\partial \mathrm{I}_{1}}$. A Neo-Hookean material, e.g. $\frac{\partial \mathrm{W}}{\partial \mathrm{I}_{2}}=0$, would plot as a horizontal 1ine. As can be seen in Figures 3-5, none of the materials exhibits either Mooney-Rivlin or Neo-Hookean behavior upon loading, although the urethane-silicone is very close to exhibiting the Mooney-Rivlin type behavior. Both the NBS Butyl and the Polyolefin elastomers show minima in the reduced stress. The unloading plots for the materials show a large time dependent component to the behavior of the materials. If the materials were elastic, the load and unload curves would reproduce. However, the unload curve in all cases is considerably different from the loading curve. The fact that the reduced stress goes to zero before $1 / \lambda$ equals one is a manifestation of the viscoelastic nature of the materials. The amount of set at the completion of the experiments was measured and is listed in Table 3.

In summarizing this section, we note that the constant rate of strain tests conducted on the three materials indicate that all of the materials exhibit different properties in simple stress-strain tests. Also, Mooney-Rivlin plots of the data indicate that the materials are not simple elastic solids. They exhibit viscoelastic behavior which is manifested in the differences in the load and unload behavior and permanent set after deformation. 


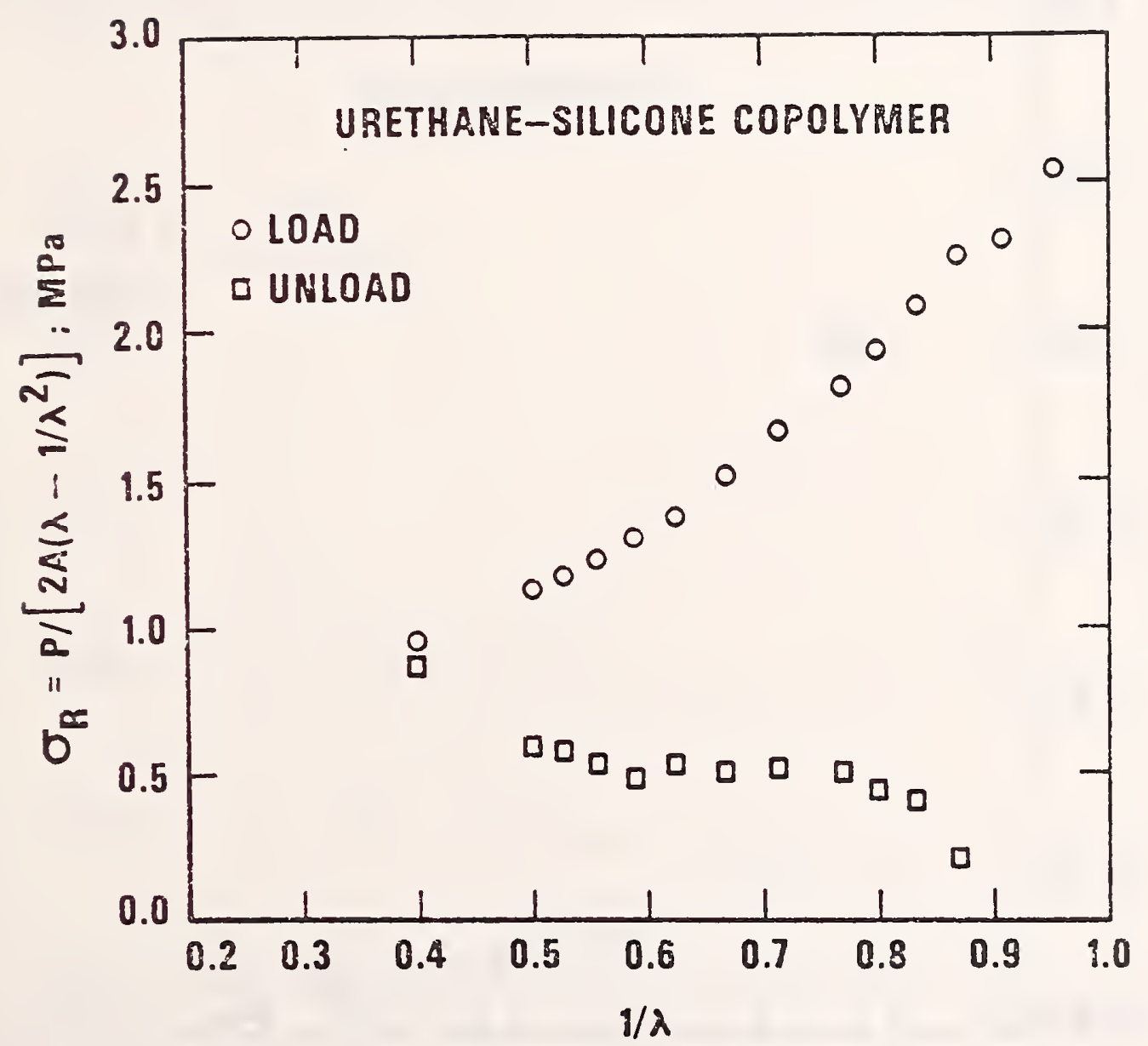

Fig. 3. Mooney-Rivlin plot for urethane-silicone copolymer. Differences between load and unload plots are due to viscoelastic behavior of the material. 


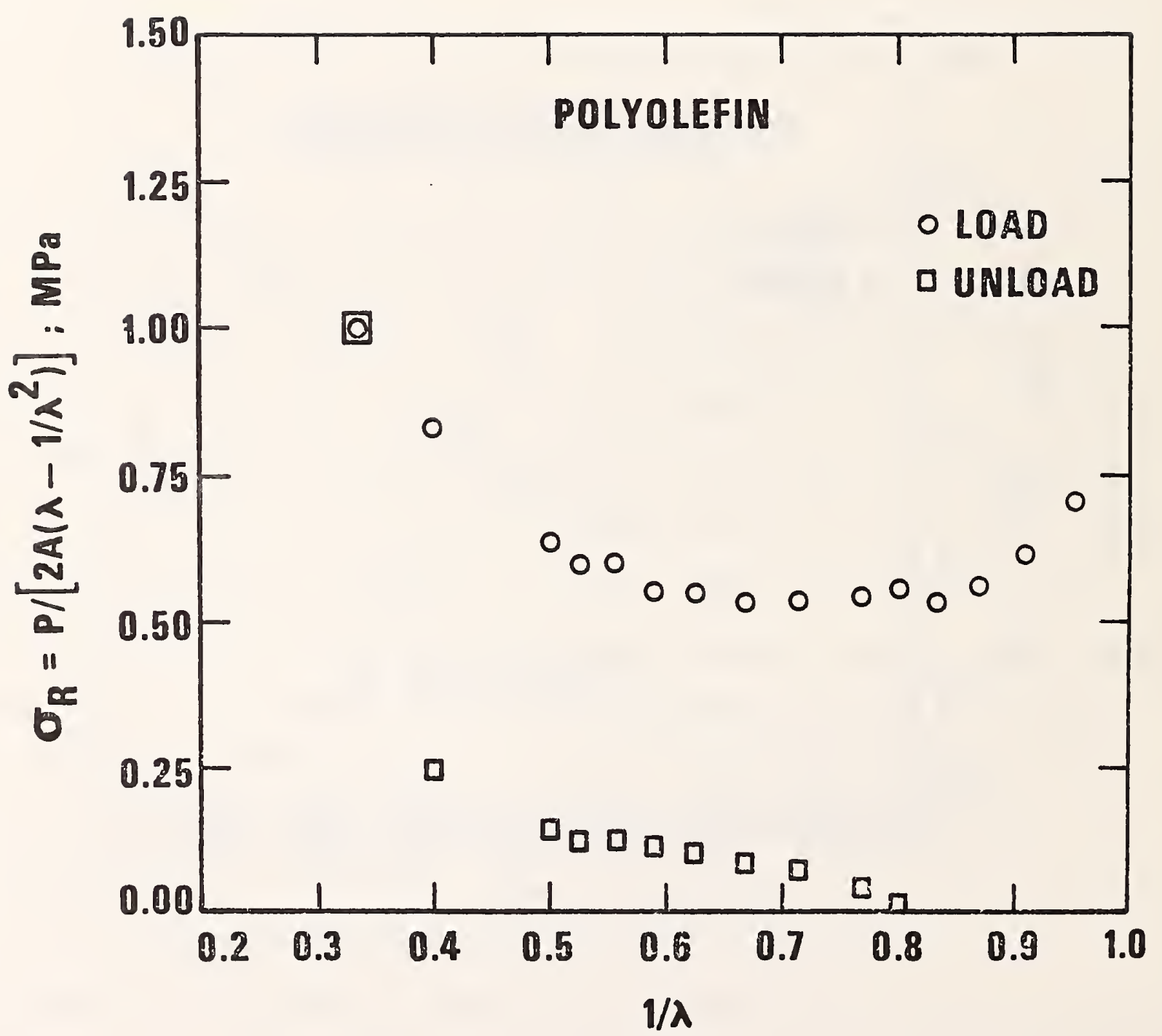

Fig. 4. Mooney-Rivlin plot for Polyolefin elastomer. Differences between load and unload plots are due to the viscoelastic behavior of the material. 


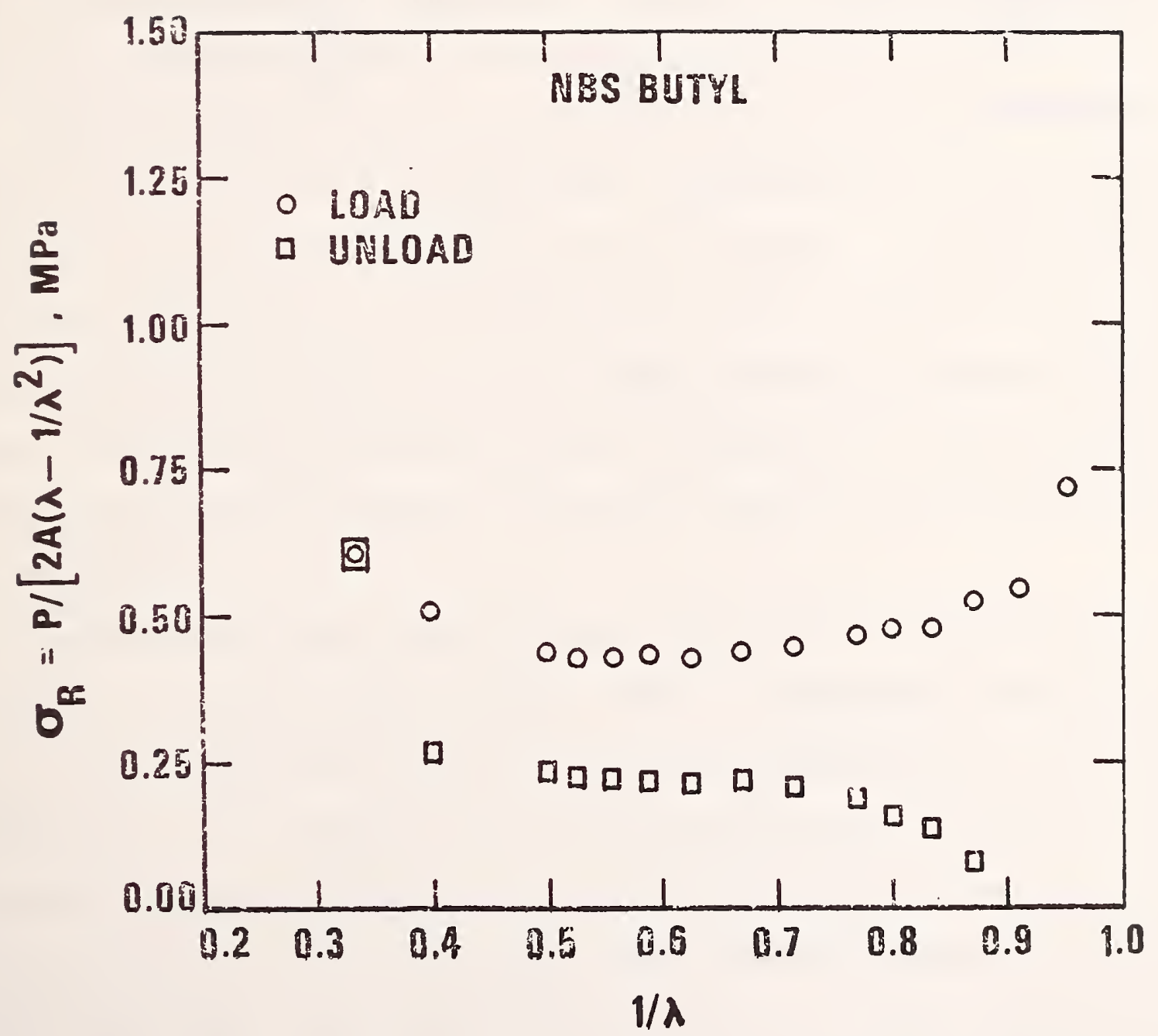

Fig. 5. Mooney-Rivlin plot for NBS Butyl Rubber. Differences between load and unload plots are due to the viscoelastic behavior of the material. 
Table 3

Permanent Set of Elastomers After Load/Unload Cycle at $0.1 \mathrm{~cm} / \mathrm{min}$.

Material

Urethane-silicone

Polyolefin

NBS Buty1
Permanent Set

$10 \%$

$21 \%$

$10 \%$ 
C. Creep of NBS Butyl Rubber

In order to begin the baseline characterization of the NBS Butyl Rubber, we have begun dead load testing of dumbbell specimens in which creep and time to fail are measured. Also, a prototype creep tank for testing in simulated physiologic media was constructed and tests are being conducted in both air and $0.15 \mathrm{~N}$ Saline. A11 tests are being conducted at room temperature $\left(23 \pm 1^{\circ} \mathrm{C}\right)$.

Figure 6 shows the creep of the NBS Butyl in air and Figure 7 shows its creep behavior in the $.15 \mathrm{~N}$ Saline. There appears to be no significant difference in the creep rates in air and in Saline. At this time, however, too few specimens have failed to allow us to construct a time to break curve. When available, the data will be used to test the linear additivity of damage concept by comparison with fatigue tests. This should then provide guidance in determining the form of a nonlinear damage law which may be required to successfully describe the failure behavior of this elastomer.

One point which needs to be discussed is the creep of the Butyl Rubber in $.15 \mathrm{~N}$ Saline. As can be seen in Figure 7, there is considerable "jerkiness" to the data. This is postulated to be due to the sticking and slipping of the Teflon pulleys used in the creep tank. This indicates either that the tank design may need to be changed to eliminate the requirement for pulleys or that much lower friction pulleys will need to be found. This is important because at the low load levels being used, a load of only $0.25 \mathrm{~N}$ can change the stress in the material by $5 \%$.

Finally, the question arises as to what simulated physiologic solution to use in characterizing the CAD materials. We have initially selected the $.15 \mathrm{~N}$ Saline due to its ease of use. Should any hydrolytic degradation mechanim be at work in the elastomer degradation it should be determined by this test. However the problem of actual blood constituents (such as lipids) playing a role in elastomer degradation needs to be considered. We are, therefore, considering using either serum or a lipid 


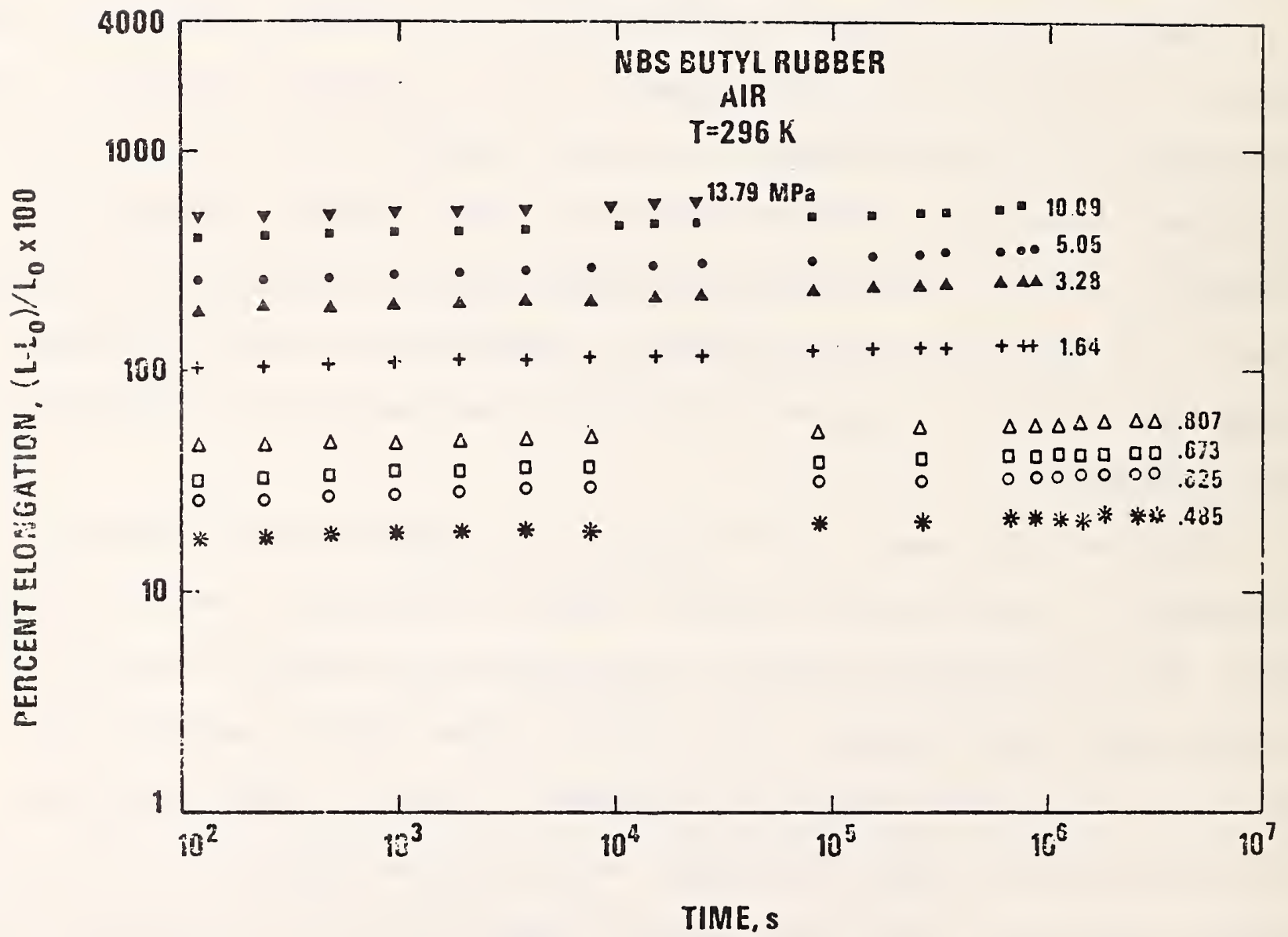

Fig. 6. Creep of NBS Butyl Rubber in air. 


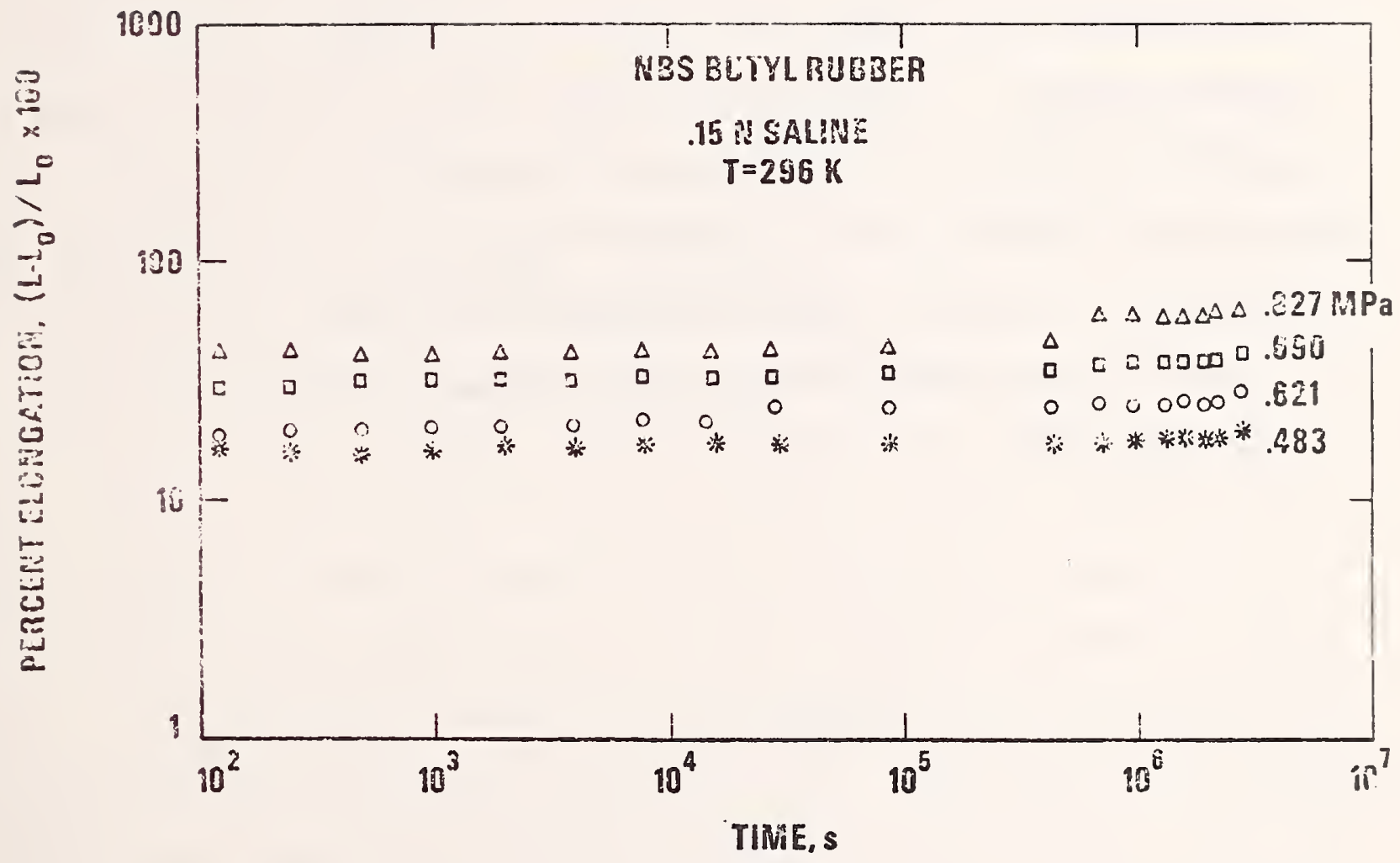

Fig. 7. Creep of NBS Butyl Rubber in $0.15 N$ Saline solution. 
solution with a bacteriostat to conduct some of our tests. We expect to use air and saline environments for the development of the test methodology and to then use the more difficult environment for selected tests.

D. Summary

Preliminary mechanical tests show significant differences in behavior among the three elastomers examined. Stress-strain behavior to failure shows that the urethane-silicone has a high initial modulus and very high ultimate strength. The polyolefin elastomer has lower initial modulus and lower ultimate strength than the urethane-silicone, but it exhibits higher stiffness in the intermediate strain range. The NBS Butyl Rubber chosen as an internal standard has the lowest initial modulus, a relatively low tensile strength and exhibits the highest elongation to failure.

Tests on the NBS Butyl indicate little difference in creep rate in air or in $.15 \mathrm{~N}$ Saline at $23^{\circ} \mathrm{C}$. 
4.

Characterization of the Urethane-silicone Film by Infrared Spectroscopy

Specimens for infrared (IR) spectroscopic studies were taken from an

intra-aortic circulatory assist device furnished by Dr. Emery Nyilas. Attenuated total reflection (ATR) IR spectra were recorded using a Digilab Fourier Transform interferometer and the transformed interferograms (transmission or absorption spectra) were stored digitally which facilitated comparisons of ATR spectra from different surfaces of the intra-aortic device. Infrared spectra were recorded on undeformed specimens as well as on specimens which had been extended $250 \%$ uniaxially (in the long axis direction of the intra-aortic device). Changes in the ATR infrared spectra were observed between the surface which was in contact with air (air-facing) and the surface which was in contact with the substrate during fabrication. No detectable differences were observed in the IR spectra of the same surface before and after deformation. Absorption spectra of the two surfaces are shown in Fig. 8a and $8 b$ and the difference between the two in Fig. 8c. Spectral differences between ATR spectra in the $650-1250 \mathrm{~cm}^{-1}$ region which are evident by visual comparison are greatly accentuated by subtraction as shown in Fig. 8c. Qualitative differences have been

previously observed between the ATR infrared spectrum of the air-facing surface and the substrate-facing surface and the ratio of optical density at 792 and $769 \mathrm{~cm}^{-1}$ shown to correlate with the degree of hemocompatibility. Monitoring IR spectral changes during mechanical testing may be useful as a qualitative measure of hemocompatibility. The quantitative difference spectrum shown in Fig. $8 c$ can be interpreted as arising from an increased concentration of poly(dimethyl siloxane) in the penetration depth of the evanescent wave for the substrate-facing surface as compared to the air-facing surface. Band maxima in the IR spectrum of PDMS [4], are compared to those of the difference spectrum in Table 5. All IR bands between 650 and $1275 \mathrm{~cm}^{-1}$ in the PDMS spectrum can be accourted for in the differenco spectrum, both by frequency and intensity. Small frequency shifts in the urethane-silicone spectrum 


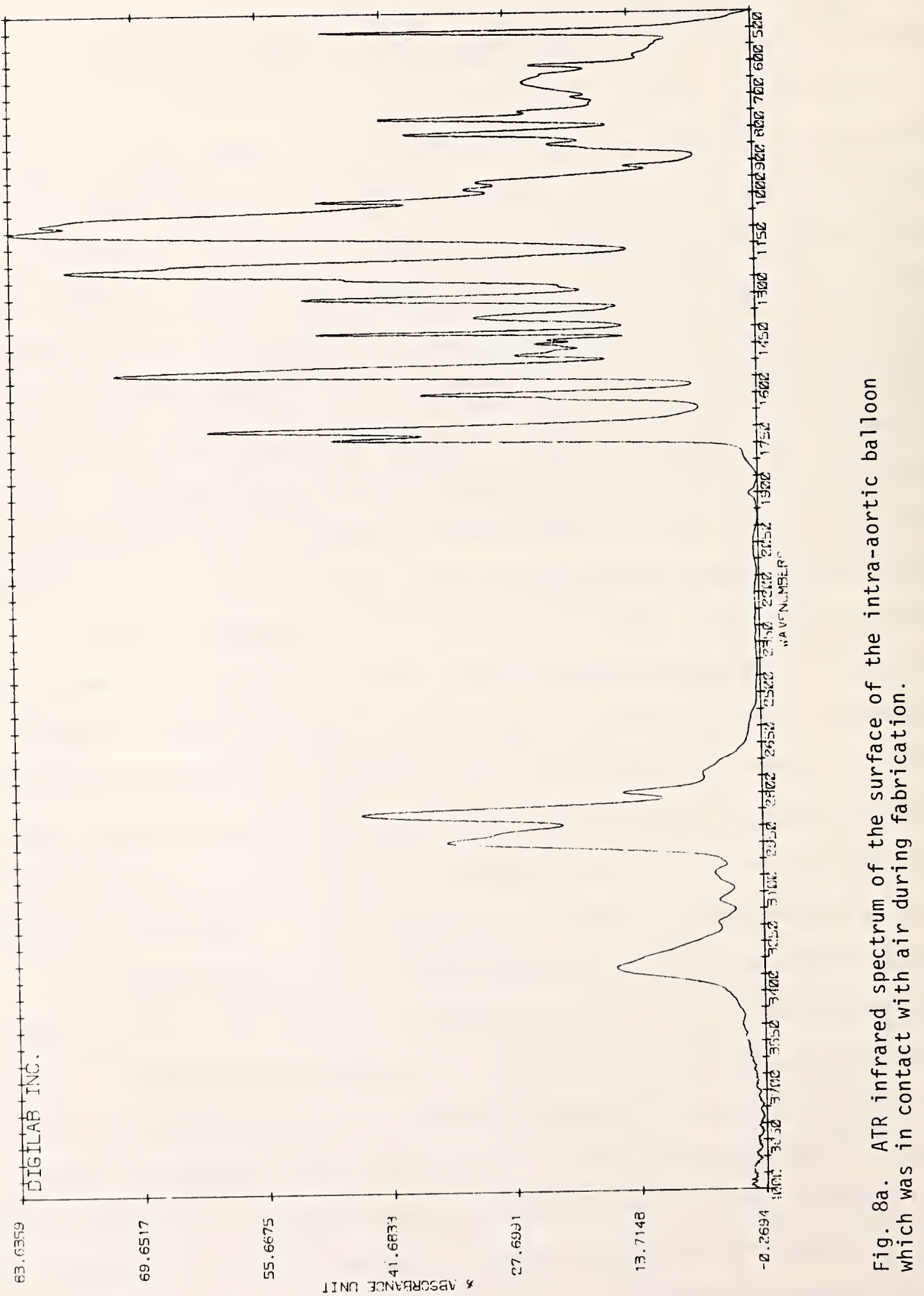




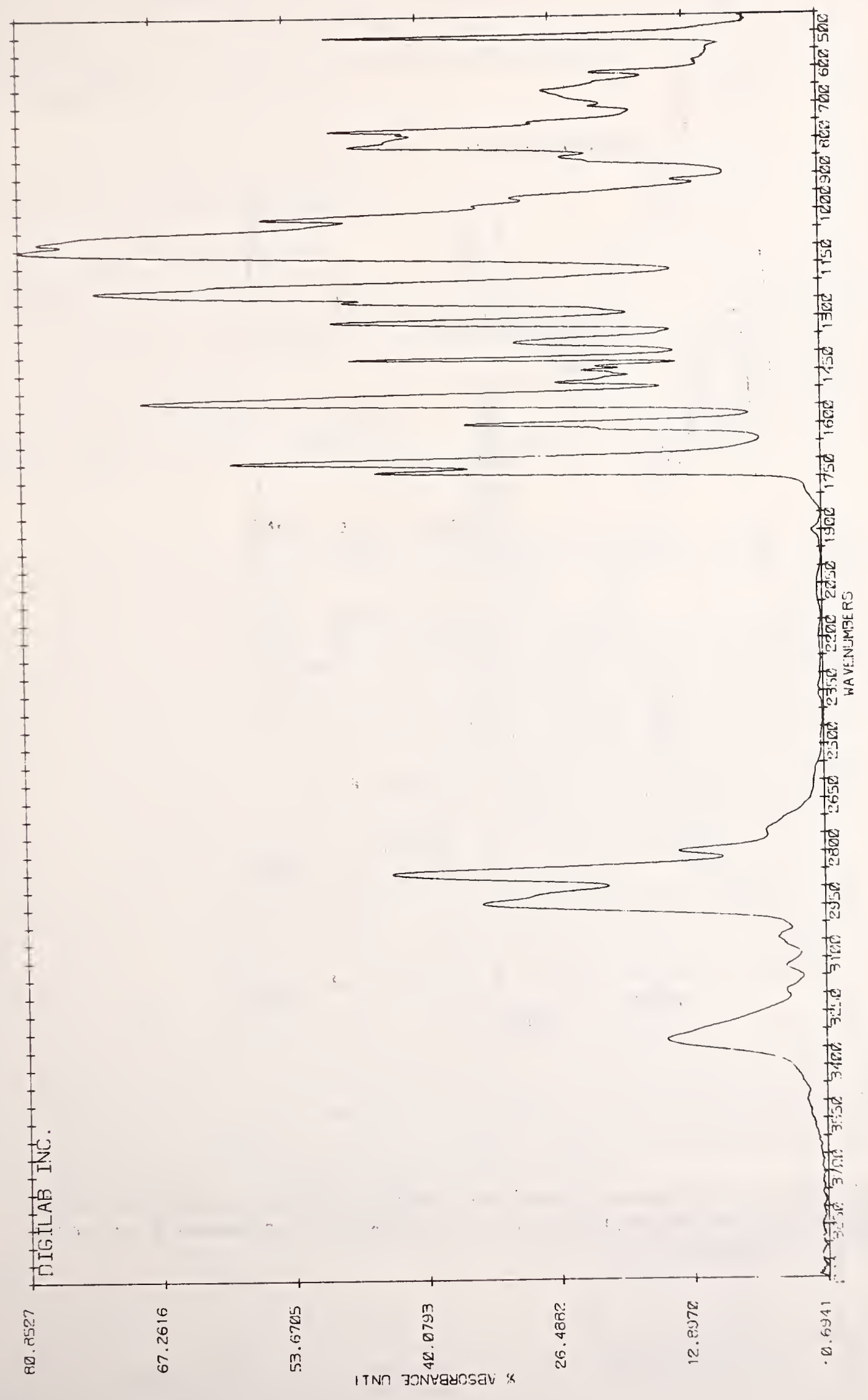

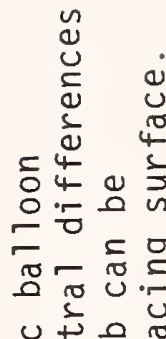

u文 $+$ ई 응워 \%

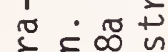
$+0 \infty$ 을 됴 is o 0 은

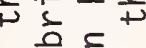
4 पष उ บ 记 $4 \stackrel{5}{4}$ ปे ज 0 던 당ㅇㅇ $+\stackrel{0}{2} \frac{0}{0}$ 4 U 음 E ज 0

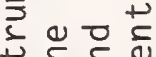
tᄃㄷㅇ Uष 드응 ज小 ० $\overline{3}$ 는 d (1) 넝응 넏ㄷㄷ ᄃ U $=$ 딴 둥요 绾 욜 $\infty$ ․․ .

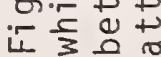




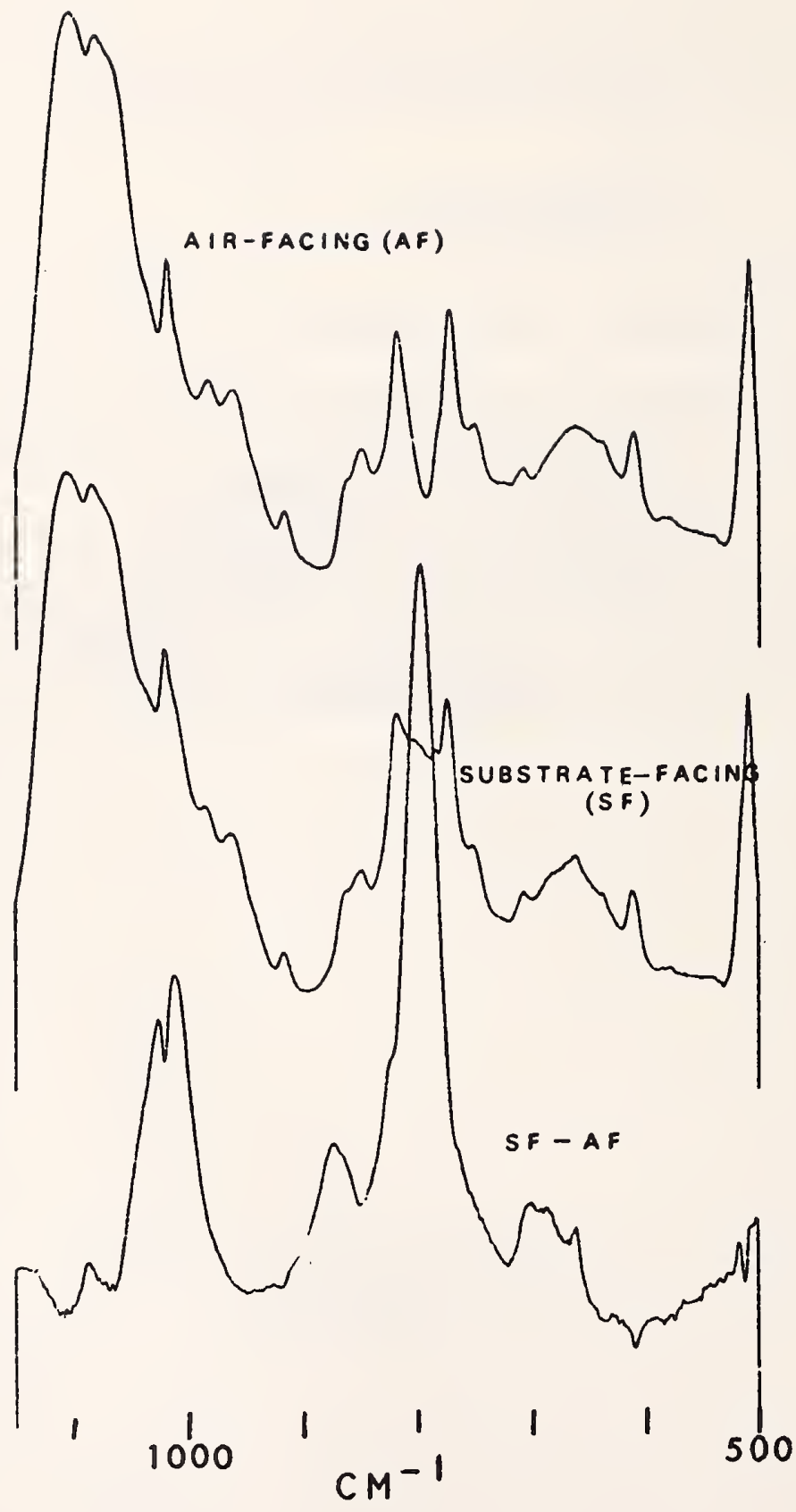

Fig. 8c. ATR infrared difference spectrum, SUBSTRATE-FACING minus AIR-FACING spectral frequencies and intensities are in substantial agreement with the IR data of PDMS, see Table 5. 
NBS. I14A (REV. 7.73)

\begin{tabular}{|c|c|c|c|}
\hline $\begin{array}{l}\text { U.S. DEPT. OF COMM. } \\
\text { BIBLIOGRAPHIC DATA } \\
\text { SHEET }\end{array}$ & $\begin{array}{l}\text { 1. I'UHBLIC ATION OR RIEPORT NO. } \\
\text { NBSIR } 79-1741\end{array}$ & $\begin{array}{l}\text { 2. Gov't Accession } \\
\text { No. }\end{array}$ & 3. Recipient's Accession No. \\
\hline \multirow{2}{*}{\multicolumn{3}{|c|}{$\begin{array}{l}\text { 4. TITLI: ANid suliTITL: } \\
\text { Fhysical Testing of Polymers for Use in Circulatory } \\
\text { Assist Devices }\end{array}$}} & $\begin{array}{l}\text { 5. Publication Date } \\
7-78\end{array}$ \\
\hline & & & 6. Performing Organization Code \\
\hline \multicolumn{3}{|c|}{$\begin{array}{ll}\text { 7. AUTHOR(S) } & \text { R. W. Penn and G. B. McKenna } \\
\end{array}$} & 8. Performing Organ. Report No. \\
\hline \multicolumn{3}{|c|}{$\begin{array}{l}\text { 9. PERFORMING ORGANIZATION NAME AND ADDRESS } \\
\text { NATIONAL BUREAU OF STANDARDS } \\
\text { DEPARTMENT OF COMMERCE } \\
\text { WASHINGTON, D.C. } 20234\end{array}$} & $\begin{array}{l}\text { 10. Project/Task/W'ork Unit No. } \\
\text { 11. Contract/Grant No. } \\
\text { YOl-HV-8-0003 }\end{array}$ \\
\hline \multicolumn{3}{|c|}{$\begin{array}{l}\text { 12. Sponsoring Organization Name and Complete Address (Street, City, State, ZIP) } \\
\text { Devices and Technology Branch } \\
\text { Division of Heart and Vascular Diseases } \\
\text { National Heart, Lung, and Blood Institute }\end{array}$} & $\begin{array}{l}\text { 13. Type of Report \& Period } \\
\text { Covered } \\
10-77 \text { to } 8-78 \\
\text { 14. Sponsoring Agency Code }\end{array}$ \\
\hline
\end{tabular}

15. SUPPLEMENTARY NOTES

16. ABSTRACT (A 200-word or less factual summary of most signiticant information. If document includes a significant bibliography or literature survey, mention it here.)

The concept of linear additive damage has been used to relate sinusoidal fatigue data with creep failure time data on two polymers. Deviations of fatigue data from predictions made from creep failure time data were found to be in opposite directions for a glassy and a semicrystalline polymer. Further work will extend this study to elastomers and candidate biocompatible materials. Specimens of Avcothane 51, obtained from rejected intra-aortic balloons, reflection spectroscopy, as well as by optical microscopy. Significant differences were observed between the two surfaces of the intra-aortic balloon similar to those which had been previously reported.

Optical microscopy has revealed circular features near the surface of the balloon wall which we are tempted to characterize as regions of segregated PDMS on a much grosser scale than has been previously reported.

We have prepared carefully controlled samples of an NBS standard butyl rubber and distributed test specimens to other investigators involved in physical testing of polymers for use in circulatory assist devices. This material has mechanical properties similar to candidate biocompatible materials and may be useful as an interlaboratory standard and for test method development.

Preliminary design and construction of a biaxial fatigue test cell has been completed. Fatigue experiments on butyl rubber using this device have indicated that only minor modifications will be necessary before initiation of fatigue testing on candidate biomaterials. A multiposition test station for these cells is being assembled

i7. KEY W'ORDS (six to twelve entries; alphabetical order; capitalize only the first letter of the first key uord unless a proper name; separated by semicolons) Additive damage; biaxial fatigue; biomaterials; circulatory assist devices; fatigue of polymers; mechanical testing.

Unlimited

For Official Distribution. Do Not Release to NTIS

Order From Sup. of Doc., U.S. Government Printing Office Washington, D.C. 20402, SI) C.at. No.C.13

Order From Narional Technical Information Service (NTIS) Springficld, Virginia 22151

\begin{tabular}{|l|l|}
\hline $\begin{array}{l}\text { 19. SECURITY CLASS } \\
\text { (THIS REPURT) }\end{array}$ & 21. NG. OF PAGES \\
UNCLASSIFIED & \\
\hline $\begin{array}{l}\text { 26. SECURITY CLASS } \\
\text { (TIIS PAGE) }\end{array}$ & 22. PriCC \\
UNCLASSIFIED & USCOMM.DC 29u22.074
\end{tabular}



Comparison of IR band frequencies of PDMS and those obtained in the difference spectrum, Fig. 8c.

$\begin{array}{lll}\begin{array}{l}\text { Band frequencies }\left(\mathrm{cm}^{-1}\right) \\ \text { Dond intensities }\end{array} & \\ \text { Difference } & \text { Spectrum } & \\ 660 \mathrm{~W} & 661 \mathrm{~W} & \text { Assignments } \\ 685 \mathrm{~W} & 687 \mathrm{~W} & \text { skeletal deformation } \\ 700 \mathrm{~W} & 702 \mathrm{~W} & \text { C-Si-C deformation } \\ 800 \mathrm{~S} & 794 \mathrm{~S} & \text { Si-C stretch } \\ 820 \mathrm{Sh} & 822 \mathrm{Sh} & \text { Si-C stretch } \\ 862 \mathrm{M} & 873 \mathrm{M} & \text { methyl rock } \\ & 1012 \mathrm{~S} & \\ 1020 \mathrm{~S} & 1025 \mathrm{~S} & \text { Si-0-Si asymmetric stretch } \\ 1093 \mathrm{~S} & 1087 \mathrm{~W} & \text { symmetric methyl deformation } \\ 1263 \mathrm{~S} & 1252 \mathrm{Sh}^{\mathrm{b}} & \end{array}$

a. S, strong absorption; M, medium absorption, $W$, weak absorption; Sh, shoulder.

b. From comparison of the spectra in Fig. la and $b$. 
can be accounted for by interactions of PDMS with the surrounding urethane matrix. One additional band, at $1012 \mathrm{~cm}^{-1}$, is observed in the difference spectrum and its origin is unknown at this time. The consistent agreement between the difference spectrum peak frequencies and the band frequencies of PDMS supports the notion that PDMS is preferentially situated near the substrate-facing surface. 
5. Microscopic Examination of Urethane-silicone Film

The urethane-silicone film taken from a reject intra-aortic balloon was also examined under the optical microscope.

It is of interest to note, in connection with the evidence for differences in composition between the inner (substrate-facing) and outer (air-facing) parts of the wall of the intra-aortic balloon, that a gross difference in morphology was observed under the light optical microscope between the region close to the inner part of the wall as compared with the outer part. Specifically, the inner region exhibits sharply outlined circular or quasi-circular features (diameter usually in the range $5 \mu \mathrm{m}-20 \mu \mathrm{m})$. These features are illustrated at low magnification in Fig. 9 and at higher magnification in Fig. 10a. In both Fig. 9 and 10a the balloon wall is lying on the microscope stage with the inner surface facing upwards. The microscope was focused, as closely as could be judged, on the inner surface in Fig. 9 and Fig. 10a and at slightly increasing depths (but still close to the inner surface) in Figs. 10b, c. The overlapping between the outlines of neighboring circles clearly shows that these features are not coplanar. The important aspect to note is that no circular features such as those just described are present near the outer part of the wall.

The origins and nature of the circular features illustrated in Figs. 9 and 10 are not known to us at this stage, nor do we know whether their occurrence is typical of the inner (substrate-facing) region of all urethane-silicone membranes or sheets. In view of the results from the ATR experiments, it is tempting to speculate that the circular features are regions of segregated PDMS. We note, however, that this would represent segregation on a much grosser scale than has been previously suggested by Nyilas and Ward, [5]. 


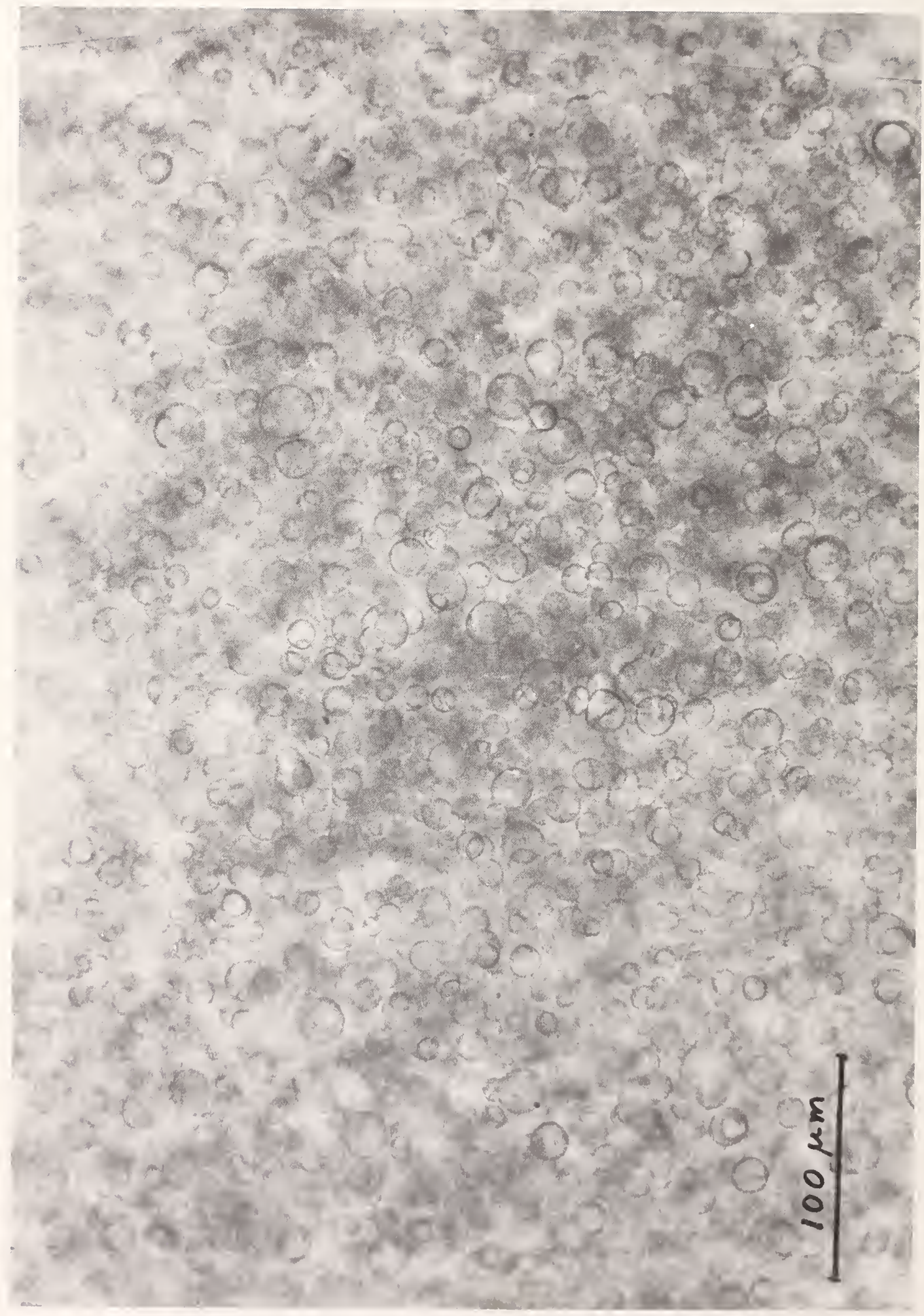

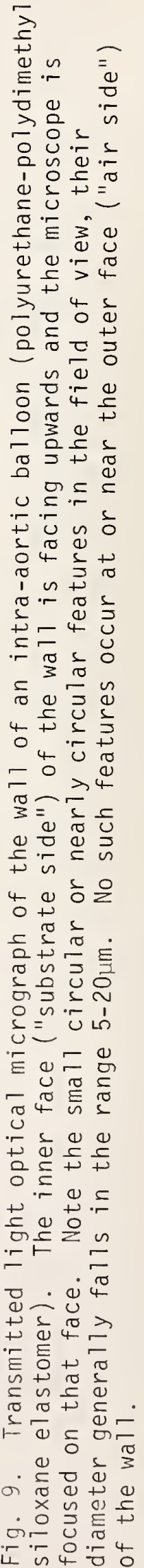




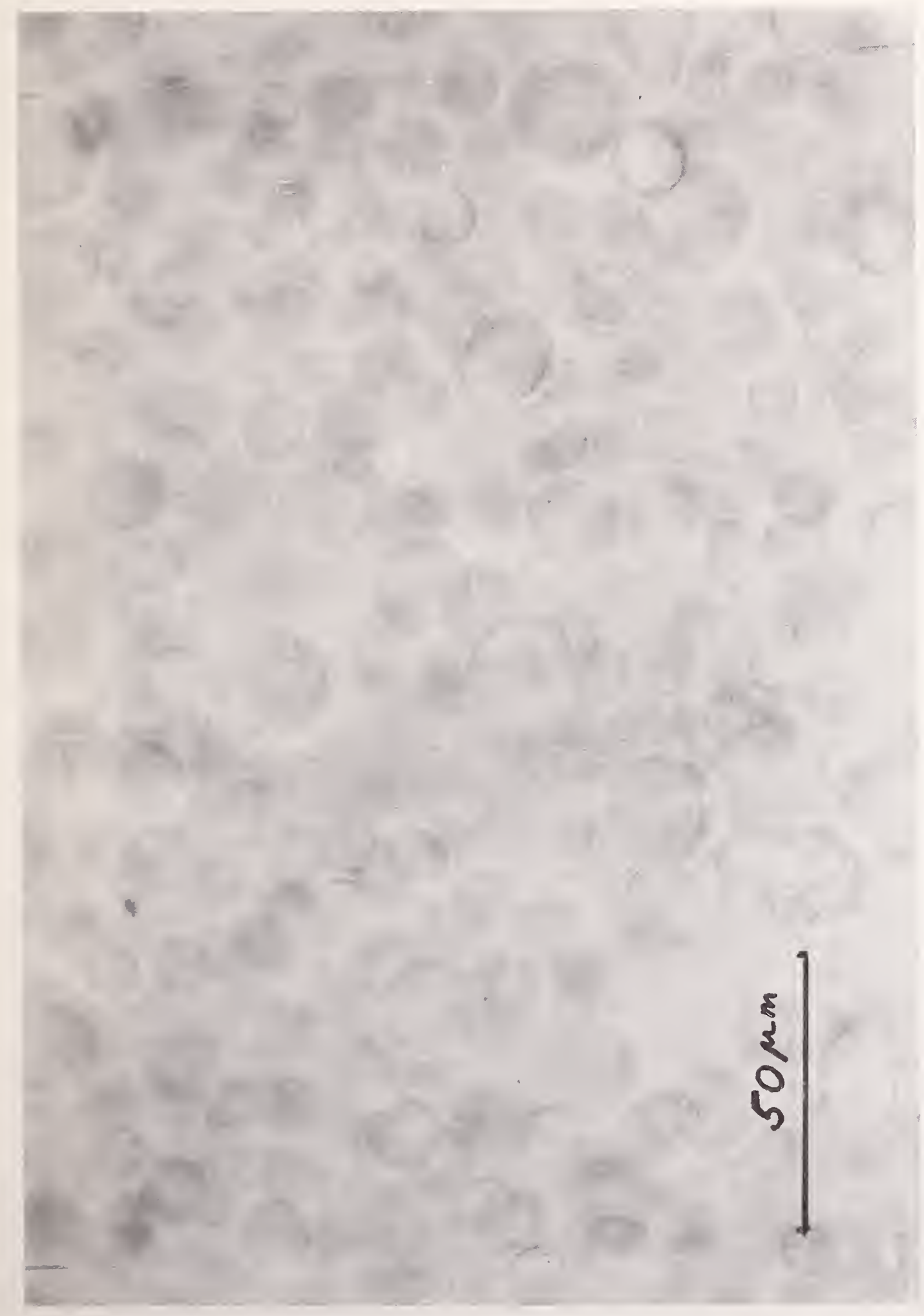


용

뭄 


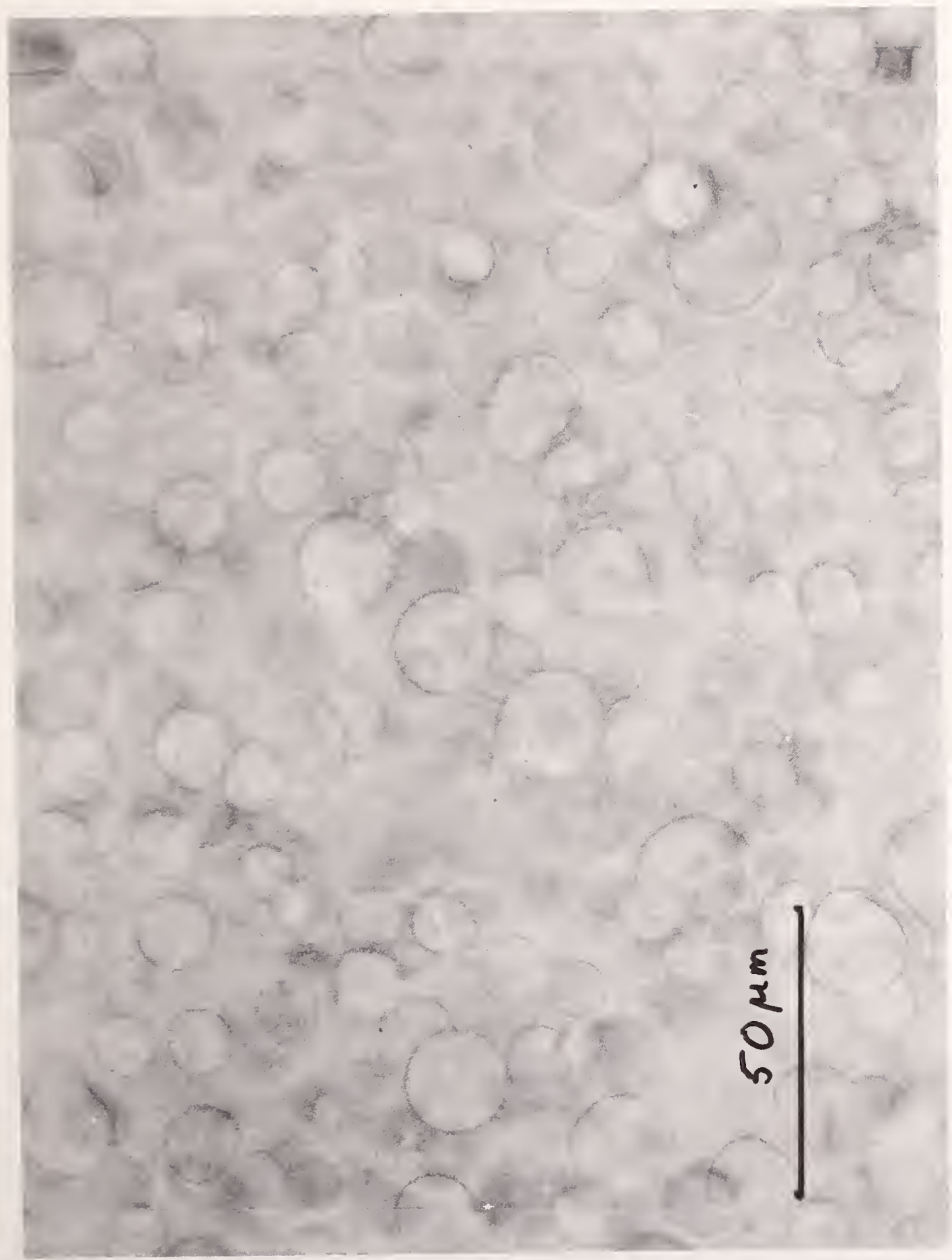

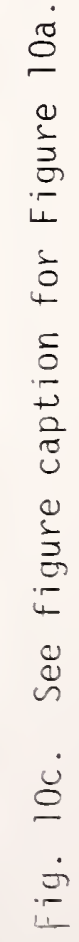




\section{Biaxial Fatigue Cell Development}

In all of the proposed designs of circulatory assist devices that we have seen, elastomeric materials are used for various purposes such as diaphragms, bladders, valves, and tubulature. In all of these applications the materials are required to withstand cyclic multiaxial stresses and strains. Since the bulk moduli of the elastomers proposed for these applications are much higher than their shear moduli, it is reasonable to treat them as incompressible so that biaxial testing is sufficient for complete evaluation. Further, failure may be expected to be accelerated much more by positive stresses than by compressive stresses. We have, therefore, chosen to develop an experimentally simple disc inflation test. In this test, a circular disc of material is clamped at its edges and subjected to a pressure difference across its faces. Many isotropic elastomers are found to deform to a shape closely approximating a segment of a sphere. (James, et.al. [6]). The deformation at the pole is equi-biaxial extension $\left(\lambda_{1}=\lambda_{2}=\lambda, \lambda_{3}=1 / \lambda^{2}\right)$. That at the edge of the disc is pure shear $\left(\lambda_{1}=\lambda_{,} \lambda_{2}=1, \lambda_{3}=1 / \lambda\right)$. The most damaging deformation is thus near the center of the disc and previous workers have found that most failures occur there.

We have designed a test cell shown in Figure 11. It is composed of two glass flange joints one of which is a flat flange while the other is grooved for an 0-ring. The inner diameter of the flat flange is only slightly less than the mean diameter of the 0 -ring. The test sample is clamped between the grooved flange and the 0 -ring and it is inflated so that it deforms around the 0 -ring into the larger flat flange joint without chafing against the glass cell. The sample is approximately one mm thick. 


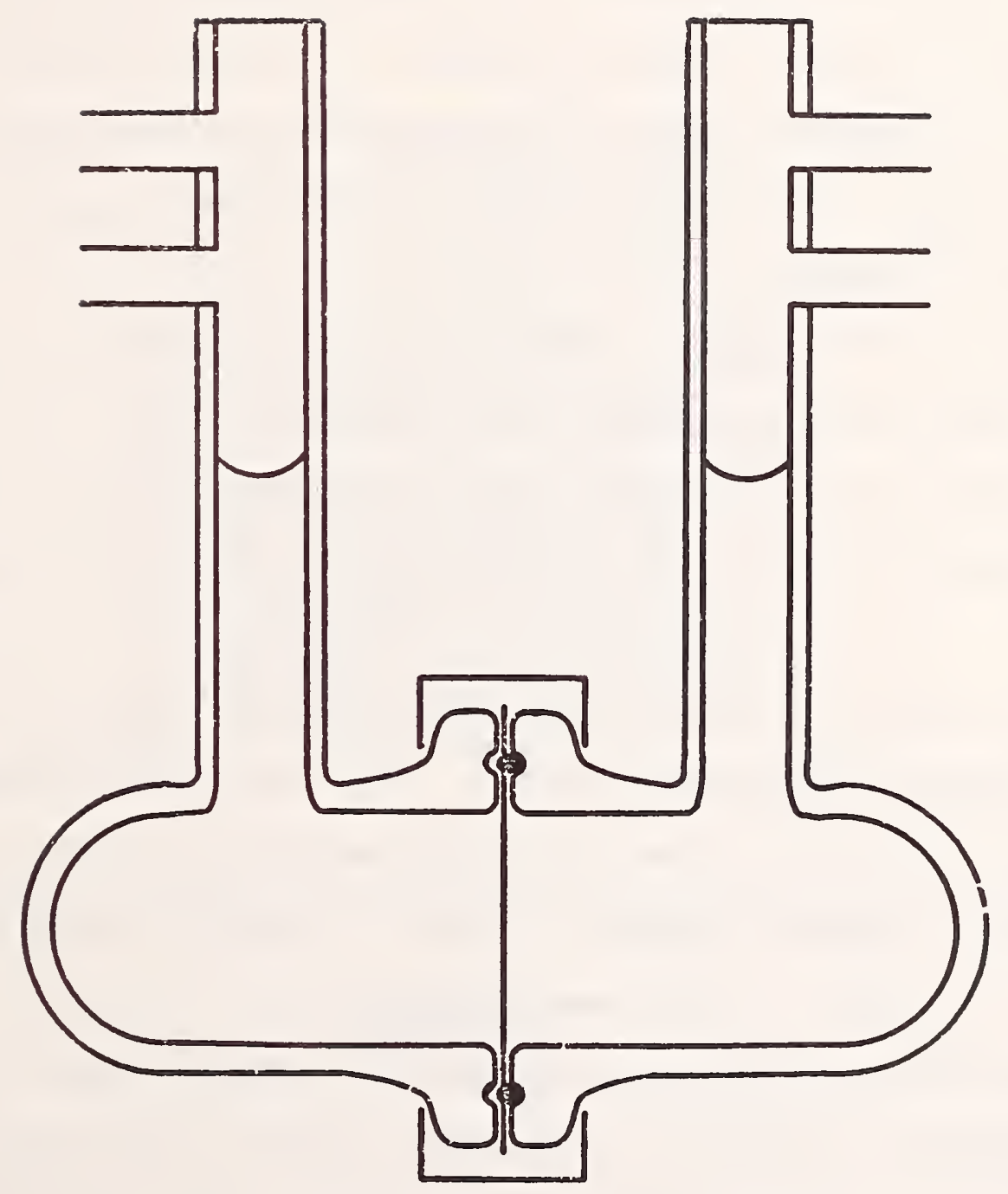

Fig. 11. Biaxial Fatigue Test Ce11. A six $\mathrm{cm}$ diameter test specimen is clamped between two glass flange joints and deformed to an approximate spherical segment by applying pressure pulses. 
As mentioned above, the sample deforms into a shape approximating a segment of a sphere. The volume of this segment can be determined from measurements of the height of the liquid in the vertical tubes of the cell. Assuming the spherical geometry, one can calculate the extension ratio at the pole of the sample and its radius of curvature. This permits the calculation of the stress in the material from the pressure difference. A calibration curve is shown in Figure 12. The extension ratio is $\lambda$ and the stress $\sigma=K P / t_{0}$ where $P$ is the pressure difference across the sheet which has undeformed thickness, $t_{0}$ and $\mathrm{K}$ is a calibration constant.

Pressure is applied from a reservoir tank and controlled by a motor driven stop-cock which alternately connects one side of the test cell to the reservoir and then vents it to the atmosphere. We have been operating at a rate of three pressure pulses per second. An oscillogram showing the pressure pulses is shown in Figure 13.

Several problems with the apparatus have appeared. First, with the maximum amplitudes which we anticipate using $(\lambda=1.5)$, considerable splashing occurs in the liquid in the vertical tubes. This might be best controlled by enlarging these tubes. We have had some success by floating discs of polystyrene foam on the surfaces of the liquid. Second, wear of the stop-cock valves causes a slow drift of the amplitude of the pressure pulse applied. This will require regular adjustment for compensation. The stop-cock valves have a service life of about two months and will require replacement at about this interval. Third, the inertia of the liquid in the apparatus contributes to the pressure amplitude experienced by the sample. A rough calculation shows that this error is 1 ess than $1 \%$ at the highest amplitude and that it is proportional to the square of the amplitude. Finally, the rate of evaporation from the test cell is considerably higher than anticipated due to the air cycling. 


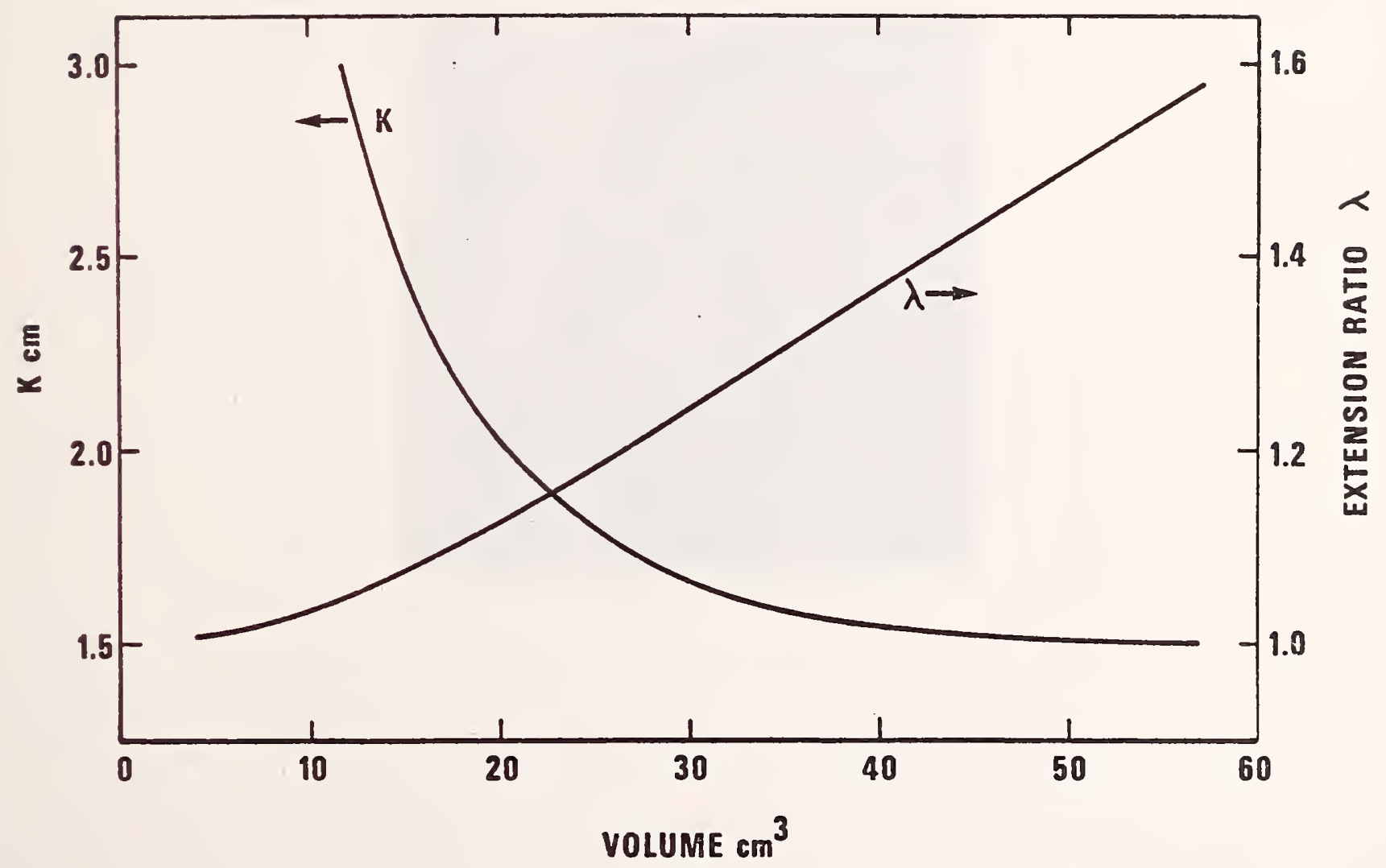

Fig. 12. Calibration curve for the disc inflation test. From measurement of the volume of the inflated circular disc one can obtain the extension ratio at the pole and the stress factor: $\sigma=\mathrm{KP} / \mathrm{t}_{0}$, where $\mathrm{P}$ is the pressure difference and $t_{0}$ the original thickness. 


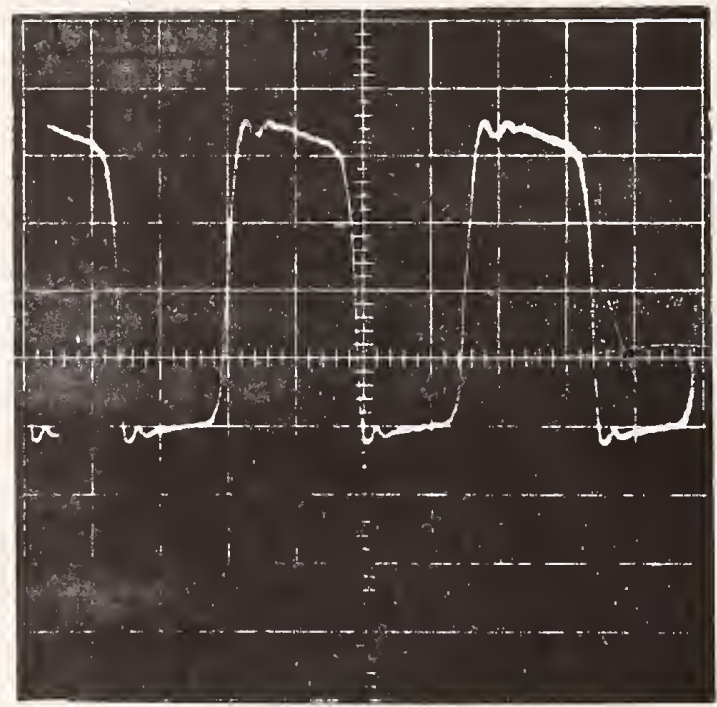

Fig. 13. Oscillogram of pressure pulses. Horizontal scale 0.1 second per division. Vertical scale 3 psi per division. The motorized valve producing these pulses has operated reliably for more than $5 \times 10^{6}$ cycles. 
Two samples of the butyl rubber have been tested thus far. They lasted with pressure amplitude of about 10 psi for 23 days $\left(6 \times 10^{6}\right.$ cycles $)$ and with pressure amplitude of 15 psi for less than two days $\left(0.5 \times 10^{6}\right.$ cycles $)$. Their strain amplitudes were approximately 1.3 and 1.5 respectively. They both failed by growth of a small crack near the center of the sample growing in a radial direction. 


\section{References}

1. Coleman, B. D., J. Poly. Sci., 22, 447 (1956).

2. Coleman, B. D., J.Appl. Phys., 29, 968 (1957).

3. Green, A. E. and Adkins, J. E., Large Elastic Deformations, Clarendon Press, Oxford, 1970.

4. Hummel, D. C., "Infrared Spectra of Polymers in the Medium and Long Wavelength Regions," Interscience, 1966, 'New York.

5. Nyilas, E. and Ward, R. S., J. Biomed. Mater. Res. Symposium, No. 8, pp 69-84 (1977).

6. James, A. G., Green, A., and Simpson, G. M., J. Appl. Poly. Sci., 19, 2033 (1975).

7. Roberts, B. J., and Benzies, J. B., Proc. Int. Rubber Conf., Brighton, 1977. 
